\title{
The adverse consequences of mephedrone use: a case series
}

\author{
Kirsty Mackay, ${ }^{1}$ Mark Taylor, ${ }^{1}$ Neeraj Bajaj ${ }^{2}$
}

The Psychiatrist (2011), 35, 203-205, doi: 10.1192/pb.bp.110.032433

${ }^{1} \mathrm{NHS}$ Lothian; ${ }^{2} \mathrm{NHS}$ Greater Glasgow and Clyde

Correspondence to Mark Taylor (marktaylor2@nhs.net)

First received 25 Aug 2010, final revision 1 Nov 2010, accepted

7 Dec 2010

\begin{abstract}
Aims and method Mephedrone is a cathinone with amphetamine-like stimulant effects, and is a commonly used recreational drug. The adverse effects of mephedrone use have not been extensively studied. All individuals who self-presented between January and June 2010 to the emergency departments and acute mental health services in Edinburgh and Falkirk with adverse effects of self-reported mephedrone use were identified.
\end{abstract}

Results Twenty cases were identified and analysed. Severe agitation was the most common presenting problem (70\%), with $40 \%$ of individuals developing psychotic symptoms and a further $20 \%$ reporting low mood and suicidality. One person died by suicide.

Clinical implications Mephedrone can produce amphetamine-like adverse psychological intoxication effects, particularly in those with a history of mental illness. Clinicians should consider advising patients on the adverse effects of mephedrone, where relevant.

Declaration of interest None.
Mephedrone (4-methylmethcathinone) is a semisynthetic stimulant manufactured from cathinone, the active ingredient of the African shrub khat, and has been marketed as plant food or bath salts. Cathinone is structurally very similar to amphetamine and can be considered as the $\beta-$ keto analogue of amphetamine. ${ }^{1}$ The effects on monoamine neurotransmission confirm the cathinone mechanism of action to be similar to those of amphetamines, with both groups of drugs binding to and promoting the release of monoamine transporters for dopamine, serotonin and noradrenaline. ${ }^{2,3}$ Mephedrone is usually sold as a white powder in capsules or zip-lock bags and is most commonly either snorted ('insufflated') or taken orally ('bombed'). It costs between $£ 10$ and $£ 30$ per gram; doses are generally between 0.5 and $1 \mathrm{~g}$, with some reports of binges up to $10 \mathrm{~g}$ in a session. ${ }^{4}$ The desirable psychoactive effects of mephedrone include euphoria, empathy, stimulation, intensification of sensory experience (e.g. music appreciation), mild sexual stimulation, mood enhancement, decreased hostility/insecurity and increased insight.,

Mephedrone use in the UK grew rapidly in 2009 and early 2010, with one self-reported drug use survey finding it to be the fourth most frequently used drug (in the prior month) after cannabis, ecstasy and cocaine. ${ }^{5}$ A case series from 2009 revealed agitation as the most commonly experienced sign of toxicity, occurring in $53 \%$ of the 15 individuals. $^{6}$

There have been a number of deaths reportedly linked with mephedrone use. ${ }^{1}$ The UK Advisory Council on the Misuse of Drugs (ACMD) recommendation that cathinone compounds such as mephedrone be classified as class B drugs came into effect in April 2010. The UK is the first country to place a generic ban on all cathinone compounds.

Literature review revealed little data available on psychiatric symptoms and the implications for mental health associated with mephedrone use. A few crosssectional and case-control studies found an interaction between khat use and mental disorder, ${ }^{7}$ but nothing outwith the popular press and the ACMD report on the specific psychotropic effects of mephedrone was identified.

We aimed to examine the occurrence of psychiatric symptoms due primarily to mephedrone intoxication occurring in patients presenting to Edinburgh and Falkirk health services.

\section{Method}

We identified patients presenting between January and June 2010 to the emergency departments or mental health services in Edinburgh and Falkirk with adverse effects of mephedrone use. Mephedrone ingestion was self-reported, as was other substance misuse. A questionnaire was designed to retrospectively collect case-note data, and this was applied to all identified cases. Data collected included: age; gender; previous psychiatric history; substance misuse; mephedrone use; psychiatric and physical symptoms relating to mephedrone use; and need for hospital admission. All identifying information was removed from the data. 


\section{Results}

Twenty cases of mephedrone use associated with adverse psychological sequelae were ascertained from Edinburgh $(n=14)$ and Falkirk $(n=6)$ (Table 1 ; for full details see online Table DS1). The psychiatric symptoms noted contemporaneously ranged from agitation through to florid psychotic symptoms including auditory, visual and tactile hallucinations as well as paranoid delusions. The majority of patients $(n=17)$ were male, and age at time of presentation was $19-59$ years, with most individuals $(n=14)$ falling in the 19-29 years range. Only five individuals presented with adverse effects following their first use of mephedrone, with the remaining patients reporting regular or heavy use prior to presentation. Alcohol was a complicating factor in $60 \%$ of presentations.

The most common psychological symptom was agitation, occurring in more than $70 \%$ of cases. In most individuals the agitation was severe and accompanied by either aggression or abnormal behaviour. A fifth of individuals presented with acute low mood and suicidality which had not been present before mephedrone ingestion. Psychotic symptoms were present in $40 \%$ of individuals, with $88 \%$ of these reporting either daily or heavy mephedrone use for at least 4 weeks prior to presentation and $75 \%$ having had a prior history of mental illness. Psychiatric symptoms and psychological distress responded in a predictable manner to appropriate pharmacotherapy.

\section{Discussion}

This is the first known case series documenting the adverse psychological or psychiatric effects of mephedrone use. Before its reclassification, mephedrone was aggressively marketed by various online suppliers as a 'legal high' - a legal alternative to cocaine and amphetamine, which in the UK could also be purchased in specialised 'head' shops.

Case reports and case series are traditionally thought of as methodologically weak and rank low in the hierarchy of evidence. Recognised areas of weakness in this series are that all mephedrone use is self-reported, as there is no routine toxicology screening to confirm the presence of the drug. Currently, routine laboratory testing is not available for mephedrone in the National Health Service in Scotland, although testing of hair, saliva and urine for mephedrone has recently been developed by the private sector.

Another weakness is that in some cases there was little information available on the amount of mephedrone consumed and (heavy) usage was self-reported. It is also

\begin{tabular}{|c|c|c|}
\hline Psychiatric history & Psychiatric symptoms post-mephedrone & Hospital admission \\
\hline $\begin{array}{l}\text { Previous psychotic episode with affective } \\
\text { symptoms }\end{array}$ & $\begin{array}{l}\text { Thought block. Paranoid delusions. } \\
\text { Auditory hallucinations. Agitation }\end{array}$ & Yes \\
\hline $\begin{array}{l}\text { Chronic depression } \\
\text { Drug-induced psychosis }\end{array}$ & $\begin{array}{l}\text { Paranoid delusions. Auditory hallucinations. } \\
\text { Ideas of reference. Severe agitation }\end{array}$ & Yes \\
\hline Delusional disorder & $\begin{array}{l}\text { Acutely floridly psychotic. Paranoid ideas. } \\
\text { Auditory hallucinations. Agitation. Suicide }\end{array}$ & Died prior to admission \\
\hline None & $\begin{array}{l}\text { Agitation. Aggression. Fluctuating on Glasgow } \\
\text { Coma Scale }\end{array}$ & Overnight in general ward \\
\hline None & Acute suicidality. Impulsive overdose & No \\
\hline None & Acute agitation & No \\
\hline None & $\begin{array}{l}\text { Bizarre behaviour for } 4 \mathrm{~h} \text {. Banging head } \\
\text { on a wall. Severe agitation }\end{array}$ & No \\
\hline None & Agitation, anxiety and insomnia & No \\
\hline Harmful use of alcohol & Agitation & No \\
\hline None & Aggression and agitation & No \\
\hline None & Anxiety and agitation & No \\
\hline None & Agitation. Bizarre behaviour & No \\
\hline Alcohol dependance syndrome & $\begin{array}{l}\text { Severe agitation. Auditory and visual } \\
\text { hallucinations. Suicidal ideas }\end{array}$ & Yes \\
\hline Low mood & Low mood. Suicidal ideas & No \\
\hline Depression & Delusions. Tactile hallucinations & Yes \\
\hline None & Paranoid delusions. Visual hallucinations & Yes \\
\hline $\begin{array}{l}\text { Previous suicidal ideas in context of social } \\
\text { crisis }\end{array}$ & $\begin{array}{l}\text { Low mood and suicidal ideas. Aggression } \\
\text { and assaultive behaviour }\end{array}$ & No \\
\hline Anxiety & Increased anxiety and insomnia & Yes \\
\hline $\begin{array}{l}\text { Transient drug-induced psychosis } \\
\text { Depression }\end{array}$ & Paranoid delusions. Auditory hallucinations & Yes \\
\hline Self-harm in context of social crisis & $\begin{array}{l}\text { Paranoid delusion. Auditory and visual } \\
\text { hallucinations. Agitation. Self-harm }\end{array}$ & Yes \\
\hline
\end{tabular}


difficult to ascertain how common the occurrence of these adverse events is, given that no accurate rate of population use is available. Although we acknowledge the limitations of this paper, it is difficult to see how the psychological effects of mephedrone could easily be studied. Another problem is that there is little published literature on the pharmacokinetics or pharmacodynamics of mephedrone in animals or human volunteers and available information on the effects of mephedrone is limited to unconfirmed user reports. Furthermore, a person may believe they are using mephedrone as sold, but the precise purity, dose or even nature of the compound may not be transparent. It appears that the desired effects and common adverse effects are similar to those seen with other stimulant drugs such as 3,4-methylenedioxymethamphetamine (MDMA), amphetamines and cocaine. From information available to date it would appear that mephedrone not only is structurally similar to amphetamine, but appears to share common negative psychological side-effects with it, which may be more pronounced in those with a history of mental illness.

In this case series, of the eight patients presenting with florid psychotic symptoms following mephedrone ingestion, four had a history of psychotic illness and two had a history of depression. Two patients were taking antipsychotic medication at time of presentation. This finding would appear to follow a similar pattern to results which have been shown in previous studies looking at stimulant-induced psychotic symptoms. A systematic review in 2004 indicated that stimulant use could result in a short-lived psychotic reaction, more pronounced in those with pre-existing psychotic symptoms, and was unaffected by adherence to regular antipsychotic medication. ${ }^{8}$ Over $65 \%$ of our sample reported regular or heavy use of mephedrone prior to presentation, with $88 \%$ of the patients who presented with psychotic symptoms also reporting heavy use. Although data on dependence are currently limited to case reports which suggest that individuals can rapidly become regular users, with some reporting early cravings for mephedrone, ${ }^{9}$ the analogy to amphetamines would suggest that chronic mephedrone use is likely to carry a similar risk of dependency. ${ }^{10}$ A report from the European Monitoring Centre for Drugs and Drug Addiction in 2010 commented that the more severe unwanted effects of mephedrone appear (anecdotally) to be associated with higher doses or prolonged use. ${ }^{11}$

Suicides involving mephedrone were widely reported in the popular press, although few have been substantiated by toxicology results. In this case series one patient died by suicide following an acute increase in psychotic symptoms after ingesting mephedrone (self-reported ingestion), but it is hard to draw conclusions with regard to the suicideinducing potential of mephedrone.

Despite the limitations of these and other related data, it is clear that mephedrone use can result in both physical and mental harm, similar in nature to that caused by other controlled stimulant drugs. The ACDM has been criticised for prematurely recommending that mephedrone be classified as a class B drug, ${ }^{12}$ but our data would suggest that mephedrone use can have serious harmful consequences. However, market forces have meant that as soon as one substance is made illegal, protean alternatives are produced ('Ivory Wave' would be one example), which in turn lead to further presentations to emergency services. More work needs to be done in ascertaining the risks to health posed by mephedrone and by the so-called 'legal highs' - just because something is legal does not mean it is safe.

\section{Acknowledgements}

We thank Carole Haxton, the mental health assessment service, and the Department of Psychological Medicine, Royal Infirmary, Edinburgh.

\section{About the authors}

Kirsty Mackay MRCPsych, Trainee Psychiatrist, Mark Taylor FRCPsych, FRANZCP, Consultant Psychiatrist, NHS Lothian, Edinburgh. Neeraj Bajaj MRCPsych, Trainee Psychiatrist, NHS Greater Glasgow and Clyde.

\section{References}

1 Advisory Council on the Misuse of Drugs. Consideration of the Cathinones. ACMD, 2010 (http://www.homeoffice.gov.uk/publications/ drugs/acmd1/acmd-cathinodes-report-2010).

2 Cozzi NV, Sievert MK, Shulgin AT, Jacobill P, Ruoho AE. Inhibition of plasma membrane monoamine transporters by beta-ketoamphetamines. Eur J Pharmacology 1999; 381: 63-9.

3 Nagai F, Nonaka R, Kamimura KSH. The effects of non-medically used drugs on monoamine neurotransmission in rat brain. Eur J Pharmacology 2007; 559: 132-7.

4 Newcombe R. Mephedrone: The Use of Mephedrone (M-cat, Meow) in Middlesbrough. Lifeline Publications, 2009.

5 Dick D, Torrance C. MixMag drugs survey. MixMag 2010; 225: 44e53.

6 Wood DM, Greene SL, Dargan PI. Clinical pattern of toxicity associated with the novel synthetic cathinone mephedrone. Emerg Med J 2010; doi:10.1136/emj.2010.092288.

7 Warfa N, Klein A, Bhui K, Leavey G, Craig T, Stansfeld SA. Khat use and mental illness: a critical review. Soc Science Med 2007; 65: 309-18.

8 Curran C, Byrappa N, McBride A. Stimulant psychosis: systematic review. Br J Psychiatry 2004; 185: 196-204.

9 Wood DM, Davies S, Puchnarewicz M, Button J, Archer R, Ramsey J, et al. Recreational use of 4-methylmethcathinone (4-MMC) presenting with sympathomimetic toxicity and confirmed by toxicological screening. Clin Toxicology 2009; 47: 733.

10 Advisory Council on the Misuse of Drugs. Methylamphetamine Review. ACMD, 2005 (http://www.homeoffice.gov.uk/publications/drugs/ acmd1/ACMD-meth-report-November-2005).

11 EMCDDA, Europol. Europol-EMCDDA Joint Report on a New Psychoactive Substance: 4-Methylmethcathinone (Mephedrone). EMCDDA, Europol, 2010 (http://www.emcdda.europa.eu/attachements.cfm/att 102496_EN_Europol-EMCDDA_Joint_Report_Mephedrone).

12 Nutt D. Mephedrone: the class D solution. Guardian 2010; 17 March (http://www.guardian.co.uk/commentisfree/2010/mar/17/ mephedrone-class-d-solution-criminalise? INTCMP=SRCH). 